Mat. Res. Bull., Vol. 22, pp. 1635-1643, 1987. Printed in the USA.

0025-5408/87 \$3.00+.00 Copyright (c) 1987 Pergamon Journals Ltd.

\title{
BISMUTH OXIDE BASED CERAMICS WITH IMPROVED ELECTRICAL AND MECHANICAL PROPERTIES
}

Part I. Preparation and characterisation.

H. Kruidhof ${ }^{*}$ K. Seshan ${ }^{*}$, B. C. Lippens Jr., P.J. Gellings and A.J. Burggraaf.

Laboratory for Inorganic Chemistry, Materials Science and Catalysis, Department of Chemical Technology, University of Twente, Post Box 217,7500 AE, Enschede, The Netherlands.

(Received June 29, 1987; Communicated by G. Blasse)

\section{ABSTRACT}

A study of the preparative variables in the synthesis of ceramics based on $\mathrm{Bi}_{2} \mathrm{O}_{3}-\mathrm{Er}_{2} \mathrm{O}_{3}$ solid solutions has shown that the best results are obtained with a coprecipitation method. Critical parameters in the synthesis are found to be $i$ ) wet milling of the precalcined powder with an appropriate liquid and ii) calcining and sintering temperatures. With the proposed method it is possible to produce monophasic, contamination free, dense and machineable ceramics suitable for practical applications.

MATERIALS INDEX : bismuth, erbium, oxides

\section{INTRODUCTION}

Stabilised $\delta$ - bismuth oxide based systems form a new generation of compounds capable of improved performance in oxygen pump and oxygen sensor applications compared to the conventionat stabilised zirconia based materials. The high temperature isomorph of bismuth oxide, the $\delta$ phase, is an excellent oxygen ion conductor (1). This phase can be stabilised to room temperature by the presence of several rare earth cations (2-7). of the various solid solutions studied, erbium oxide stabilised bismuth oxide has the highest reported ionic conductivity $(6,8)$. The solid solutions between bismuth oxide and erbium oxide are

* author for correspondance.

** On leave from Indian Petrochemical

Corporation Ltd, Baroda, India. 
stable in the range of 17.5 to 40.0 mole percent of erbium oxide $(6,8)$. From this point of view, it is essential to optimise the preparative variables in the synthesis of bismuth erbium oxide solid solutions to yield dense, monophasic, and machineable materials for use in practical applications. This paper presents the efforts undertaken to produce such materials and consists of two parts. The first part deals with the aspects of synthesis and the second part with the details of the structural and mechanical properties of the materials. Mainly, coprecipitation has been chosen for the preparation of the compounds. For the sake of comparison, samples have also been prepared by a solid state reaction between the individual oxides. As will be shown in part II of this paper (9) the method described here yields materials with superior mechanical properties.

\section{EXPER IMENTAL}

The composition that has been tried out as representative is $\left(\mathrm{BI}_{2} \mathrm{O}_{3}\right) 0.75-\left(\mathrm{Er}_{2} \mathrm{O}_{3}\right) 0.25$, henceforth indicated as BE25. The method is, however, standard for the entire range of solid solutions. The experimental details are given below.

\section{i. The coprecipitation method.}

Bismuth and erbium are coprecipitated as hydroxides from a solution of nitrates. First, the required amounts of the pure oxides $\mathrm{Bi}_{2} \mathrm{O}_{3}(99.99 \%)$ and $\mathrm{Er}_{2} \mathrm{O}_{3}(99.999 \%)$ were separately dissolved in concentrated nitric acid. These solutions were mixed and then diluted to a concentration of $0.5 \mathrm{~g} / \mathrm{ml}$. The hydroxides were coprecipitated by adding simultaneously, with constant stirring, the mixed nitrate solution and $4 \mathrm{M}$ ammonia solution to a buffer of 0.1 M ammonia solution ( $70 \mathrm{ml} / \mathrm{g}$ of the oxide) at $325 \mathrm{~K}$ and at pH around 9. Higher temperatures seemed to promote the formation of separate carbonates. Lower pH resulted in the separation of hydroxide layers. The precipitate was washed with water and oven dried at $375 \mathrm{~K}$. Washing the coprecipitate with propanol-2 to remove water in order to suppress agglomerate formation was not sultable as discussed 1 ater.

After prefiring at an appropriate temperature, the powders were subjected to a milling process for 2 hours in a satellite type miliing apparatus. Milling vessels of agate or zirconia were used. Dry miliing and miliing with water, ethanol, acetone or propano1-2 were applied. The milled products were compacted after drying in the form of cylinders of 16 to $25 \mathrm{~mm}$ diameter and 10 to $20 \mathrm{~mm}$ length by isostatic pressing at $4000 \mathrm{~kg} / \mathrm{cm}^{2}$. The compacts were sintered in air at temperatures between 1035 and $1125 \mathrm{~K}$ for 16 hours. The heating and cooling rates were $0.8 \mathrm{~K} / \mathrm{min}$. The circumference of the sintered cylinder was drilled off using a bronze coated tubular glass drill to remove any contaminated layers. The cylinder was then sliced into circular discs of the required thickness using a high speed diamond cutter. The discs were polished and finally annealed at $1000 \mathrm{~K}$ for 12 hours to relieve any stresses developed during shaping and polishing. 


\section{ii. Malic acid and Solid state reaction method}

The malic acid method is an adaptation of the citrate method used for the preparation of stabilised zirconia reported earlier (10). In this method, to a solution of bismuth and erbium nitrates, malic acid was added in the stoichiometric ratio required to convert the nitrates to malates. The solution was then heated to dryness. Further heating after drying resulted in pyrolysis of the mixture. The products were treated as mentioned in the previous section.

In the case of the solid state reaction method, standard ceramic procedures were used to prepare solid solutions starting from pure oxides.

\section{RESULTS AND DISCUSSION}

A TGA recording of a fresh coprecipitate is shown in fig.l. There is a continuous weight loss up to about $775 \mathrm{~K}$, due to $10 \mathrm{~s}$ of free and bound water from the hydroxides. The total weight loss is about $9 \%$ against the expected 1 oss of $11 \%$ for a BE25 hydroxide. This is probably because bismuth is partly present as an oxyhydroxide, BiOOH, besides $\mathrm{Bi}(\mathrm{OH})_{3}$.

The DTA curves of the samples are shown in fig.2. A freshly coprecipitated sample shows (fig. 2a), in addition to the 1 oss of water (fig. 1) two endothermic peaks at 882 and $999 \mathrm{~K}$. There is no weight loss associated with these peaks and therefore they must correspond to some isomorphic transformations. In the normal time scales they do not seem to be reversible as these transformations do not appear in the cooling cycle (also figs. $2 \mathrm{~b}$ $\& 2 c)$. When the sample was heated at $900 \mathrm{~K}$ for 160 hours the height of the peak at $999 \mathrm{k}$ was drastically reduced (fig. 2d) indicating that the transformation can occur at lower temperatures by prolonged heating. In addition a new peak was observed at $923 \mathrm{k}$. The significance of this will be discussed in part II of this paper (9). The mixed oxide precursors of the solid state reaction method also showed a peak at 999 K (fig. Le) as expected from the above observations. The powders obtained from the malic acid method did not show any changes during the DTA run. This probably stems from the fact that the decomposition of the compound formed with malic acid is strongly exothermic which results in high local temperatures. Consequently the material has already passed through the above mentioned phase transition.

To understand the changes observed in the thermal analyses, samples were heated isothermally to the temperatures of transformation and then characterised using $x-r a y$ powder diffraction. A sample heated to $1010 \mathrm{~K}$ is monophasic with the cubic fluorite phase having a cell parameter of 0.54838 nm. A sample heated to $900 \mathrm{~K}$ contained a mixture of BE25 phases, one of them being cubic. The poor crystallinity of the sample prevented determination of the exact nature of the other phase, which probably has a tetragonal symmetry. When the sample was heated at $900 \mathrm{~K}$ for 160 hours it contained only the cubic phase with a cel1 


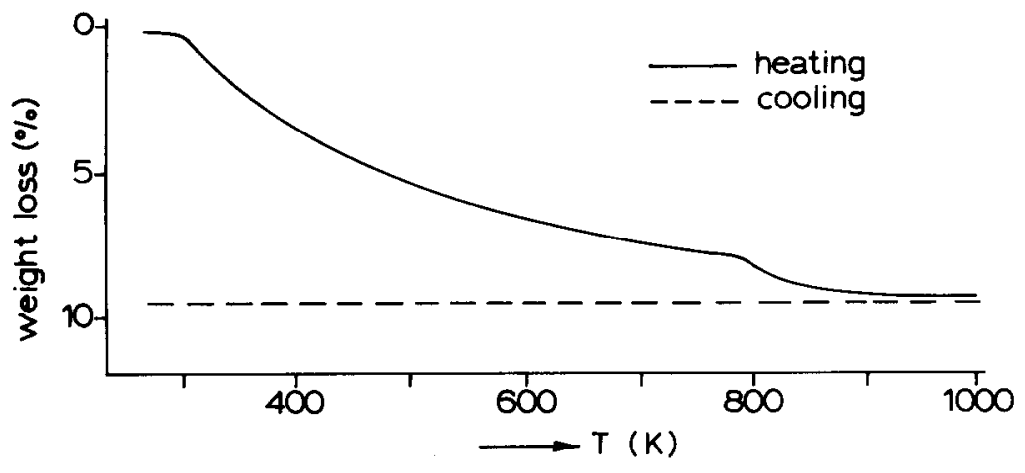

FIG. 1

Thermogravimetric analysis of BE 25 coprecipitate.

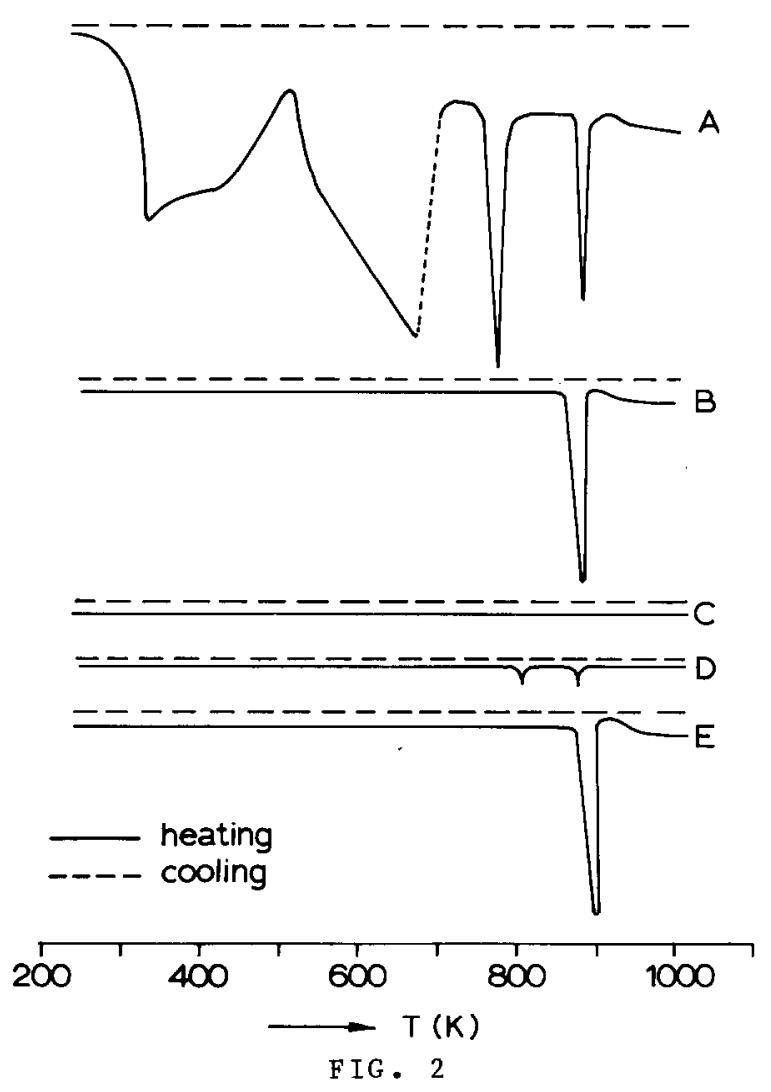

DTA curves of BE 25 samples; A. Fresh coprecipitate, B. A Heated at $900 \mathrm{~K}$ for $4 \mathrm{hrs}$, C. A Heated at $1010 \mathrm{~K}$ for 4 hrs, D. C Heated at $900 \mathrm{~K}$ for $160 \mathrm{hrs,}$. Mixture of oxides 
parameter of $0.54832 \mathrm{~nm}$. These observations, coupled with the earlier ones on thermal analyses lead to the followng conclusions. The peak at $882 \mathrm{~K}$ corresponds to the reaction between oxides for the Formation of the solid solution. This implies that the hydroxides decompose first to yield homogeneously mixed reactive oxides and the reaction takes place subsequently. The peak at $999 \mathrm{~K}$ corresponds to the complete transformation of BE25 into the cubic phase. The dynamic heating procedure in DTA simulates the short heating of four hours at $900 \mathrm{~K}$ and hence the peak at $999 \mathrm{~K}$ is observed. It seems therefore that the transformation to the cubic phase is kinetically a slow process at lower temperatures and is complete at $999 \mathrm{~K}$. This indicates that the sample prepared by coprecipitation first undergoes a reaction to yield a mixture of solid solution phases which transform further to the monophasic cubic material. In the case of the malic acid and solid state reaction methods these two stages could not be observed. The main fact which emerges from these observations is that the calcination has to be carried out above $999 \mathrm{~K}$ to avoid transformations during final sintering whtch would produce materials having inferior mechanical properties.

Washing the coprecipitate with the commonly used propanol-2 was observed to produce an organic complex which decomposed exothermally on subsequent heating, resulting in less reactive powders for sintering. The diminished sinter reactivity is probably caused by agglomerate formation during the exotheric reaction. This has not previously been described in the 1 iterature

The coprecipitates were calcined at $1010 \mathrm{~K}$ and subsequent $1 \mathrm{y}$ milled to break up agglomerates formed during calcination. Initially, milling was carried out in agate pots and this resulted in samples with poor mechanical properties. Fig. 3 shows a SEM photograph of such a sample and shows massive silica contamination. Incorporation of silica leads to sillenite type structures which extracts large amounts of bismuth, forming compositions of the type Bi ${ }_{12} \mathrm{SiO}_{20}$. This alters the bismuth/erbium stoichiometry and destabilises the solid solution. Presence of silica is considered to be one of the causes for the poor mechanical properties of the samples. The problem of silica contamination has been overcome by subsequently using zirconia milling pots.

Milling with acetone was always observed to give a green coloured powder compared to the starting yellow colour of the prefired powder. Transmission Infrared spectra in KBr of various milled samples are shown in fig. 4. The samples milled with ethano1, propano1-2 or water do not show any significant absorption bands, but the sample milled with acetone shows a spectrum similar to that of a secondary alcohol (11). It is probable that acetone reacts with the cubic bismuth erbium oxide forming a bonded secondary alcohol type complex. This reaction probably occurs due to the high surface active nature of the cubic bismuth erbium oxide phase.

The densities of the samples after sintering were in the order of $98 \%$ of the theoretical densities. Densities of samples 


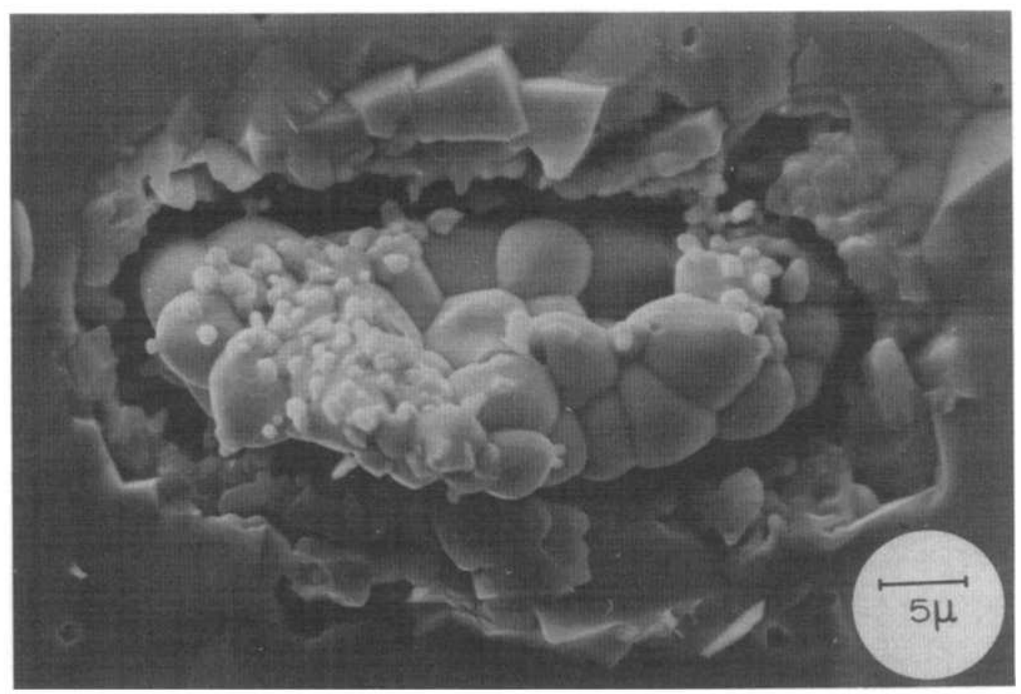

FIG. 3

SEM photograph of silica contamination in BE 25 .

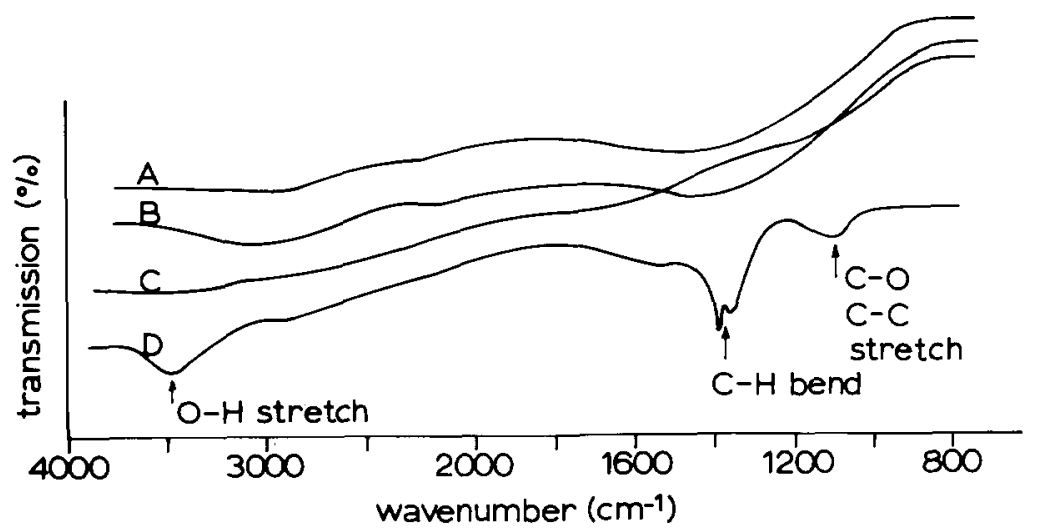

FIG. 4

Infrared spectra of BE25 samples after miliing with, A. water, B. Propano1-2, C. Ethanol D. Acetone 
obtained after milling with acetone were larger than $99.5 \%$ whereas all other methods including solid state reaction or the malic acid method and involving milling with other solvents like water, ethanol or propanol-2 at best yielded densities in the order of $98 \%$. The complex formed with acetone seems to produce a more sinter reactive powder. The details of the results obtained after each method are summarised in table 1. From this it is

TABLE 1

Sumary of properties of samples obtained by different methods

\begin{tabular}{|c|c|c|c|c|}
\hline Method & $\begin{array}{l}\text { Miling } \\
\text { medium }\end{array}$ & $\begin{array}{l}\text { Sinter temp- } \\
\text { erature }(K)\end{array}$ & $\begin{array}{c}\text { Density } \\
(\%)\end{array}$ & $\begin{array}{l}\text { Grainsize } \\
(\mu)\end{array}$ \\
\hline$--\cdots--1$ & -------1 & $-\infty---\infty----$ & ------ & ------- \\
\hline Coprec- & Acetone & 1125 & 99.5 & 15 \\
\hline ipitation & , , & 1035 & 98.2 & 04 \\
\hline method & Water & 1125 & 97.0 & -- \\
\hline, & Propanol-2 & 1125 & 98.5 & 15 \\
\hline , & Ethanol & 1125 & 97.0 & 15 \\
\hline , , & Dry & 1125 & 86.0 & -- \\
\hline So 1 id & Acetone & 1125 & 98.5 & 50 \\
\hline state method & Others & 1125 & 96.0 & 50 \\
\hline , & Dry & 1125 & 84.0 & -- \\
\hline Ma1 & Acetone & 1125 & 99.0 & 25 \\
\hline method & Dry & 1125 & 87.0 & -- \\
\hline
\end{tabular}

clear that the coprecipitation method incorporating a wet milling step with acetone produces samples superior to those obtained from the other methods, having higher packing densities and sma1ler grain sizes. A SEM photograph of such a specimen is shown in fig 5. The importance of a wet milling step with acetone is obvious from the results. In addition the microstructures which result from sintering a powder milled with acetone, has a very significant effect on the mechanical properties of the final materia1. This will be shown in part II of this paper(9). Fig.6 shows a photograph of BE25 shaped to the required sizes and geometries for investigations of these materials for oxygen sensor and oxygen pump applications.

\section{CONCLUSIONS}

1. Coprecipitation of bismuth and erbium as hydroxides provides an excellent way of producing a homogeneous starting material for the synthesis of bismuth erbium ceramics. Careful control of pH, temperature and washing procedure during coprecipitation is critical for obtaining thoroughly mixed and easily filterable precipitates.

2. A calcining temperature of at least $1010 \mathrm{~K}$ is essential for a suitable material for sintering, as at this temperature the material is completely monophasic and in the required state. Calcining below this temperature results in undesired phase transitions during subsequent sintering. A minimum sintering temperature of $1035 \mathrm{~K}$ is recommended. The two temperatures are 


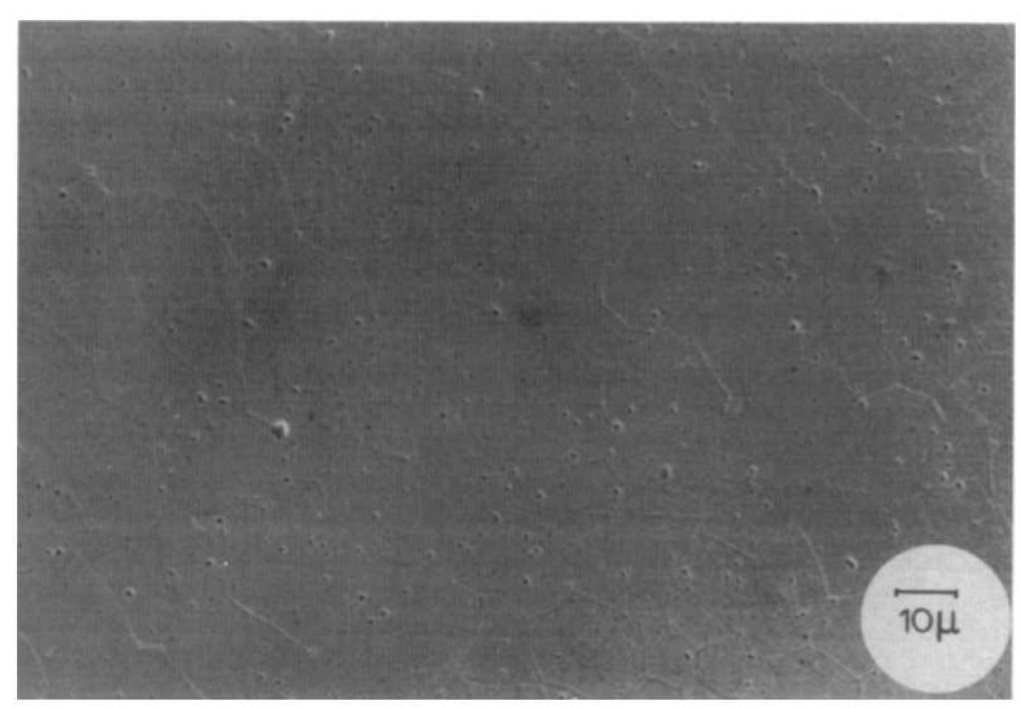

FIG. 5

SEM photograph of a finished BE25 sample.

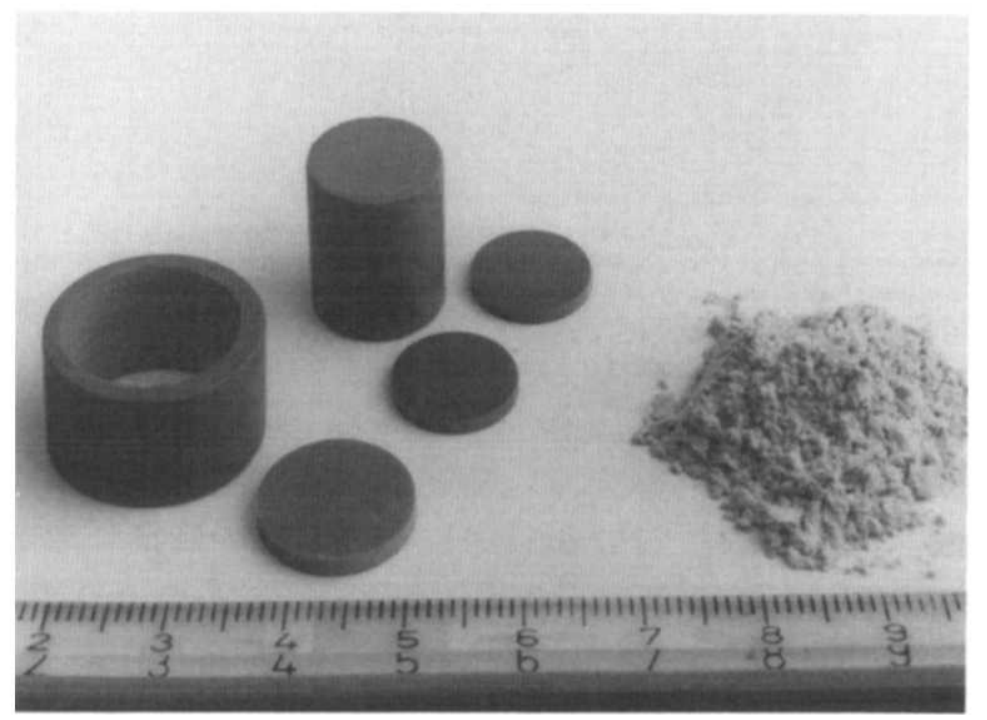

FIG. 6

Photograph of finaliy shaped products. 
close to each other indicating the easy sinterability of these compounds.

3. These compounds are easily contaminated by silica and even platinum and hence contact with these materials during the heating should be avoided. Silica forms compounds of the type Bi $\mathrm{SiO}_{2}$ with bismuth, extracting large amounts of bismuth. This affects ${ }^{2}$ the local bismuth erbium stoichiometry and destabilises the solid solution. Silica contaminated samples have therefore been observed to show poor mechanical properties (9).

4 Wet miling of the calcined powder with acetone before sintering results in superior quality of the finished product, probably by forming a complex on the powder surface and this yields final compact densities greater than $99.5 \%$ after sintering. No such complex formation has been observed with other milling media.

\section{ACKNOWLEDGEMENTS}

We aknowledge the expertise of Mr. Joep snoeyenbos of the Glass Blowing Section in shaping the samples. We also thank Dr. B. Boukamp for recording the SEM photographs. One of the authors (KS) acknowledges the award of a post doctoral fellowship from the Foundation for Applied Research (STW) in the Netherlands.

\section{REFERENCES}

1. H.A. Harwig and A.G. Gerards, J. Solid State Chem., $26,265(1978)$.

2. $\vec{M} \cdot \mathrm{J}$. Verkerk and A.J. Burggraaf, J. Electrochem. Soc., $128,75(1981)$.

3. T. Takahashi, H. Iwahara and T.Arao,

J. Appl. Electrochem., 5, 187 (1985).

4. T. Takahashi, T. Esaka and H. Iwahara, ibid.,

5, 197 , (1975).

5. T. Takahashi and H. Iwahara, ibid.

$3,65(1973)$.

6. M.J. Verkerk and A.J. Burggraaf, Solid State Ionics, $3 / 4,463,(1981)$.

7. M.J. Verkerk, G.M.H. van Velde and A.J. Burggraaf, J. Phys. Chem. Solids, 43, 1129 (1982).

8. M.J. Verkerk, K. Keizer and A.J. Burggraaf, J. App1. E1ectrochem., 10,81 (1980).

9. H. Kruidhof, K. Seshan, B.C. Lippens, P.J. Geliings and A.J. Burggraaf, Mater. Res. Bull.(to be communicated).

10. M.A.C.G. van de Graaf, T. van Dijk, M.A. de Jongh and A.J. Burggraaf, Sc. Ceram., 9, 75 (1977).

11. CRC Hand book of Spectroscopy, Volume II, Ed. J.W.Robinson CRC press, Ohio, USA (1974) 